\title{
Optimization of an efficient solid-phase enrichment medium for Salmonella detection using response surface methodology
}

\author{
Feng Tang ${ }^{1 *}{ }^{*}$, Zhi Chen ${ }^{2+}$, Feng Wang ${ }^{3}$, Hongyan $\mathrm{Hou}^{3}$, Weiyong Liu ${ }^{3}$, Han Xiao ${ }^{4}$, Jiao Hu ${ }^{5}$, Yan Xiong ${ }^{2}$, \\ Hui Zhang ${ }^{6}$, Zhongju Chen ${ }^{3}$, Hanming Peng ${ }^{7}$, Jun Lu ${ }^{8}$, Wanjun Luo ${ }^{9}$, Ying Zhao ${ }^{2}$ and Miao Lin ${ }^{10}$
}

\begin{abstract}
Salmonella is a pathogenic bacterium contributing to food poisoning and acute infectious intestinal disease. The traditional standard detection method is based on the principle of liquid phase enrichment and has a low sensitivity on targeted bacteria. We previously developed a visual immunosensor technique for efficient detection and isolation of Salmonella by applying fluorescent nanobioprobes on a specially-designed cellulose-based swab. In this study, a whole-sample solid-phase enrichment assay (WSEA) was established by optimization of the enrichment medium using response surface methodology (RSM), a powerful statistical tool for regression analysis. The optimal formula was determined as: $0.60 \%$ polyvalent poly peptone, $0.40 \%$ buffered peptone water, $0.09 \%$ ferric citrate amine, $0.24 \%$ sodium hyposulfite, $0.035 \%$ cystine, $0.01 \mu \mathrm{g} \mathrm{mL}^{-1}$ super absorbing polymer, $0.011 \%$ sodium deoxycholate, $15.00 \mu \mathrm{g} \mathrm{mL}^{-1}$ ethyl green and $30.00 \mathrm{mg} \mathrm{mL}^{-1}$ sodium selenite. Using this formula, Salmonella was visualized with naked eyes by relying on

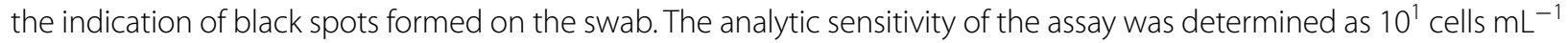
with a concentration of interfering bacteria (Escherichia coli) at $10^{5}$ cells $\mathrm{mL}^{-1}$. This optimized formula was confirmed with 4006 patients' fecal samples, in which the positive rate was $0.42 \%$ by the conventional culture-based method and $2.12 \%$ by WSEA. The optimized formulation on solid phase enrichment by RSM allows relatively quick, low-cost, and large-scale detection of Salmonella, and could be used in grassroots medical institutions.
\end{abstract}

Keywords: Salmonella, Visual detection, Solid-phase enrichment assay, Hydrogen sulfide, Response surface methodology

\section{Introduction}

Salmonella is a pathogenic bacterium contributing to food poisoning and acute infectious intestinal disease (LaRock et al. 2015; Scallan et al. 2011). Salmonella enterica can be divided into two main groups, typhoidal and non-typhoidal Salmonella. The global health impact of non-typhoidal Salmonella is high, with an estimated 93.8 million illnesses and 155,000 deaths each year (Majowicz et al. 2010). The typhoidal Salmonella causes more

\footnotetext{
*Correspondence: tang22feng66@163.com

${ }^{\dagger}$ Feng Tang and Zhi Chen contributed equally to this work

1 Department of Laboratory Medicine, Wuhan Children's Hospital

(Wuhan Maternal and Child Healthcare Hospital), Tongji Medical College,

Huazhong University of Science \& Technology, Wuhan 430016, People's

Republic of China

Full list of author information is available at the end of the article
}

than 22 million infections and 216,000 deaths per year in developing countries (Jin et al. 2017). In China, Salmonella was the most common pathogen causing food poisoning according to the annual bulletins of National Health and Family Planning Commission of China. In the US, Salmonella was also responsible for foodborne illnesses, and approximately 42,000 cases of serious salmonellosis were reported annually. However, only 7554 cases were confirmed by culture diagnostic test and 618 cases by culture-independent diagnostic test in 2016 (Marder et al. 2017).

The traditional standard detection method is based on liquid phase enrichment, which has not achieved sufficient sensitivity on bacterial enrichment and high isolation rate on Salmonella (Bell et al. 2016). A large number of false negative cases (Salmonella carriers) become 
potential sources of infection. Though some rapid detection technologies on culture-independent diagnostic test are emerging, the greatest challenge is still to obtain pure isolates, which is a prerequisite for the etiological diagnosis, molecular epidemiological analysis, and antibiotic sensitivity experiments (Langley et al. 2015; Marder et al. 2017).

In our previous study, a novel immunosensor technique for efficient detection and isolation of Salmonella was established by applying fluorescent nanobioprobes on a specially-designed cellulose-based swab (Tang et al. 2016). However, this technique is not suitable for largescale detection due to two major reasons. One is that it requires expensive instrument, such as laser scanning confocal microscope, which may not be available in many hospitals. Another reason is that it is complex to synthesize and prepare the specialized bio-probe reagent, especially at large-scales. In this study, a whole-sample solid-phase enrichment assay (WSEA) was further established through appropriate optimization and verification of the enrichment medium.

As a sulfate-reducing bacterium, Salmonella can reduce cystine or sodium thiosulfate and produce hydrogen sulfide $\left(\mathrm{H}_{2} \mathrm{~S}\right)$ (Jackson et al. 2013), which reacts with ammonium ferric citrate to produce ferrous sulfide (Gong et al. 2014). At relatively high concentrations, ferrous sulfide can form visible black spots on the surface of the specially designed cellulose-based swab. Accordingly, these essential components (cystine, sodium hyposulfite and ferric citrate amine) are the most important variables of the chromogenic reaction. In contrast to Salmonella, the $\mathrm{H}_{2} \mathrm{~S}$ reaction of Escherichia coli is negative. A more important factor that affects the sensitivity and specificity of this chromogenic reaction is the incubation medium, which is required not only to enhance the growth of Salmonella and inhibit the growth of non-Salmonella, but also to help the conversion of hydrogen sulfide to ferrous sulfide. It is difficult to evaluate and optimize these multiple factors of the medium.

Optimization of parameters by the conventional method involves changing one independent variable while unchanging all others at a fixed level. This is extremely time-consuming and expensive for a large number of variables and also may result in wrong conclusions (Tam et al. 2012). Response surface methodology (RSM) is a mathematical model that is often used to predict the response of a system to multifactor condition and evaluate the relationship among a set of controllable experimental factors and observed results. Therefore, the RSM could be used to predict the optimized medium from multiple factors (Li et al. 2018; Verma et al. 2018). RSM has been also applied in biotechnology, biopharmaceuticals, food industry, medical applications, and other fields (Abd Elrazak et al. 2013; Zhang et al. 2012). The central composite design (CCD) in RSM is an empirical statistical technique for modeling complex systems, evaluating the simultaneous effects of several factors, and searching optimum conditions for desirable responses (Mousavi et al. 2018; Dastkhoon et al. 2017). In this study, CCD was applied to optimize the formulation of the chromogenic medium for a wider applicability on different Salmonella serotypes. Multiple variables were applied to the mathematical model to predict the optimal formula, which was then evaluated using standard strains and confirmed using human fecal samples. We concluded that our optimized WSEA is an efficient and lowcost method for large-scale detection for Salmonella. It may have broad applications, especially in the grassroots medical institutions, with its low cost and ease of use.

\section{Materials and methods}

To optimize the solid-phase enrichment medium for Salmonella detection, we firstly used the CCD in RSM to mathematically predict the possible optimized media. Nine standard Salmonella strains belonging to eight major types of A-F (O:2-O:11) group were applied to one model of statistical regression analysis. In order to enhance the practicality of the method, 40 Salmonella strains belonging to 40 serotypes (O:2-O:11) from local patients were also collected and applied to another model. E. coli ATCC 25922 was used as a non-Salmonella control. These strains are listed in Table 1. The CCD system automatically generated 20 combinations from variables for enhanced production of ferrous sulfide. According to these combinations, the results of visual observation were recorded accordingly, and then the predicted response was automatically calculated. Analysis of variance (ANOVA) in CCD was used to evaluate the statistical significance and the goodness-of-fit of the model. Subsequently, the mixtures of Salmonella and $E$. coli strains were used to test the analytic sensitivity of the new assay. Ultimately, the optimized formula was confirmed with 4006 human fecal samples.

\section{Ethics}

The protocol of this study was approved by the Human Research Advisory Committees of the Wuhan Center for Disease Control and Prevention (WHCDCIRBK-2018016) and the Wuhan Children's Hospital of Tongji Medical College of Huazhong University of Science \& Technology for Medical Sciences ([2018]IEC(S140)). All procedures performed in studies involving human participants were in accordance with the ethical standards of the relevant national and institutional committees on human experimentation and with the Helsinki Declaration of 1975, revised in 2008. All participants were 
Table 1 Bacterial strains used in this study

\begin{tabular}{|c|c|}
\hline Bacterial strains & Source \\
\hline \multicolumn{2}{|l|}{ Standard strains } \\
\hline Salmonella paratyphoid A CMCC 50093 & CMCC \\
\hline Salmonella enteritidis ATCC 13076 & ATCC \\
\hline Salmonella typhi ATCC 19430 & ATCC \\
\hline Salmonella senftenberg CMCC 50105 & CMCC \\
\hline Salmonella typhimurium ATCC 14028 & ATCC \\
\hline Salmonella infanti ATCC 51741 & ATCC \\
\hline Salmonella manhattan CMCC 50152 & CMCC \\
\hline Salmonella aberdeen CMCC 50147 & CMCC \\
\hline Salmonella muenster CCAM 090010 & CCAM \\
\hline \multicolumn{2}{|l|}{ Local strains } \\
\hline $\begin{array}{l}\text { Salmonella typhi } \\
\text { Salmonella agona } \\
\text { Salmonella derby } \\
\text { Salmonella anatum } \\
\text { Salmonella enteritidis } \\
\text { Salmonella sinstorf } \\
\text { Salmonella butantan } \\
\text { Salmonella aberdeen } \\
\text { Salmonella braenderup } \\
\text { Salmonella london } \\
\text { Salmonella risen } \\
\text { Salmonella isangi } \\
\text { Salmonella muenster } \\
\text { Salmonella potsdam } \\
\text { Salmonella kentucky } \\
\text { Salmonella meleagridis } \\
\text { Salmonella cremieu } \\
\text { Salmonella saintpaul } \\
\text { Salmonella kottbus } \\
\text { Salmonella typhimurium } \\
\text { Salmonella manhattan } \\
\text { Salmonella papuana } \\
\text { Salmonella singapore } \\
\text { Salmonella mikawasima } \\
\text { Salmonella newport } \\
\text { Salmonella thompson } \\
\text { Salmonella duboin } \\
\text { Salmonella brijbhumi } \\
\text { Salmonella gallinarum-pullorum } \\
\text { Salmonella pakistan } \\
\text { Salmonella blockley } \\
\text { Salmonella senftenberg } \\
\text { Salmonella schwarzengrund } \\
\text { Salmonella mbandaka } \\
\text { Salmonella stanley } \\
\text { Salmonella eppendorf } \\
\text { Salmonella sandiego } \\
\text { Salmonella newlands } \\
\text { Salmonella paratyhi A } \\
\text { Salmonella paratyhi B } \\
\text { Sal }\end{array}$ & $\begin{array}{l}\text { All local strains were from the } \\
\text { Wuhan Centers for Disease } \\
\text { Control and Prevention }\end{array}$ \\
\hline \multicolumn{2}{|l|}{ Non-Salmonella strain } \\
\hline Escherichia coli (E. coli) ATCC 25922 & ATCC \\
\hline
\end{tabular}

ATCC American Type Culture Collection, CMCC National Center for Medical Culture Collections, CCAM Collection Center of Agricultural Microbiology

voluntary and agreed to participate in the methodological comparative study. The medical reports were still based on the results of the national standard test method.

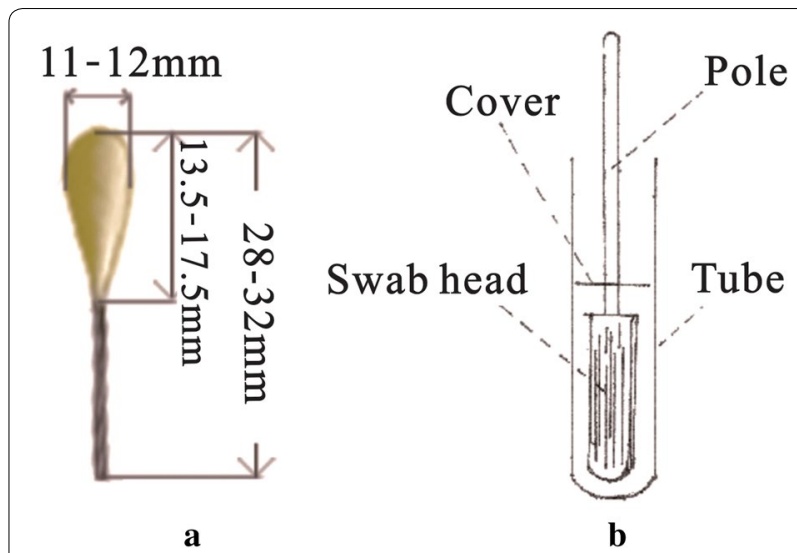

Fig. 1 A schematic diagram of the swab: a the size of the swab, and b the swab immersed in the sample tube, which is covered with a silicone plug to prevent contamination

\section{Production of swabs}

Each swab is $28.0-32.0 \mathrm{~mm}$ long and $11.0-12.0 \mathrm{~mm}$ wide with a $14.5 \mathrm{~cm}$ bamboo handle (Fig. 1a). It contains $0.18 \mathrm{~g}$ of $100 \%$ medical-grade degreasing cotton, which has the ability to absorb approximately $1000 \mu \mathrm{L}$ of medium or sample solution. The swabs were sterilized by ethylene oxide in a sterilizer $\left(900 \mathrm{mg} / \mathrm{L}, 55-60{ }^{\circ} \mathrm{C}, 6 \mathrm{~h}\right)$, and not treated with any reagents (e.g. formaldehyde or decolorizer). The swabs were immersed with sufficient medium at $25{ }^{\circ} \mathrm{C}$, then dried under sterile conditions at room temperature. When applied to culture, the sample tube was covered with a silicone plug (Fig. 1b).

\section{Detection procedures}

The bacterial samples were proportionally prepared with $10^{1}$ cells $\mathrm{mL}^{-1}$ of Salmonella and $10^{5}$ cells $\mathrm{mL}^{-1}$ of E. coli. The swabs were immersed with $1000 \mu \mathrm{L}$ of test samples at $25^{\circ} \mathrm{C}$, and then cultured for $16-24 \mathrm{~h}$ at $37^{\circ} \mathrm{C}$. From the 18 th $\mathrm{h}$ to the 24th $\mathrm{h}$ of culture, these swabs were examined with naked eyes once every $3 \mathrm{~h}$. The swabs without black spots at $24 \mathrm{~h}$ were excluded as non-Salmonella samples. The black spots on swabs were picked up with a small sterile iron hook $(15 \mathrm{~cm}$ length handle and $2 \mathrm{~mm}$ elbow) and then plated onto the xylose lysine desoxycholate (XLD) agar and modified semi-solid rappaport vassiliadis (MSRV) agar plates for isolation of positive colonies, which were incubated for $18-24 \mathrm{~h}$ at $37^{\circ} \mathrm{C}$. In this study, XLD agar, nutrient broth and MSRV agar were purchased from Qingdao Hi-Tech Industrial Park Hope Bio-Technology Co., Ltd. China.

\section{Response surface methodology (RSM) analysis of the medium used on swab}

Nine standard Salmonella strains and 40 Salmonella strains from local patients belong to 40 serotypes and 
were divided into two groups as simultaneous models. The three key variables for enhanced production of ferrous sulfide included $5 \%$ cystine, $20 \%$ sodium hyposulfite, and $10 \%$ ferric citrate amine. The basic nutrients and inhibiting ingredients used in the study contain ethyl green $15.00 \mu \mathrm{g}$, sodium selenite $30.00 \mu \mathrm{g}, 60.00 \mu \mathrm{L}$ of $10 \%$ the polyvalent polypeptone, $40.00 \mu \mathrm{L}$ of $10 \%$ buffered peptone water, and $11.00 \mu \mathrm{L}$ of $1 \%$ sodium deoxycholate, and $0.01 \mu \mathrm{g}$ of super absorbing polymer in $600.00 \mu \mathrm{L}$ of distilled water. In addition, $20 \%$ sodium carbonate was used to adjust the $\mathrm{pH}$ to 7.2 , and then made up $1.00 \mathrm{~mL}$ total with distilled water. In this study, ferric citrate amine, sodium hyposulfite and cystine were purchased from Shanghai Chemical Reagent Co., Ltd. China. Super absorbing polymer (Product number: 127284) is a polymer material based on polyacrylamide with good water absorption and water-holding capacity, and was purchased from Liaocheng City Yongxing Environmental Protection Material Co., Ltd. China.

The CCD in Design-Expert statistical software (RSM, Version 8.0.6.1; Stat-Ease Inc, Minneapolis, MN, USA) automatically generates 20 combinations from the three key factors. Data were fitted into a quadratic polynomial model to obtain optimal regression coefficients (Additional file 1). The relationships between factors and responses were evaluated by fitting the following second-order polynomial model as previously described (Li et al. 2018):

$$
Y_{i}=\beta_{0}+\sum \beta_{l} x_{i}+\sum \beta_{i j} x_{i} x_{j}+\sum \beta_{j j} x_{j}^{2}
$$

where $Y_{i}$ is the predicted response, $\beta_{0}$ is the coefficient for intercept, $\beta_{\mathrm{i}}$ is the coefficient of linear effect, $\beta_{\mathrm{ij}}$ is the coefficient of interaction effect, $\beta_{\mathrm{ji}}$ is the coefficient of quadratic effect, and $X_{i}$ and $X_{j}$ are the coded independent variables. The three variables we used for the optimization include $10 \%$ ferric citrate amine $\left(\mathrm{X}_{1}\right), 20 \%$ sodium hyposulfite $\left(\mathrm{X}_{2}\right)$, and $5 \%$ cystine $\left(\mathrm{X}_{3}\right)$. The predicted responses for nine standard Salmonella strains $\left(\mathrm{Y}_{1}\right)$ and for 40 Salmonella strains from local patients $\left(\mathrm{Y}_{2}\right)$ were derived from Eq. (1) (Li et al. 2018). ANOVA was used to evaluate the statistical significance and the goodnessof-fit of the model. The significance of every variable in the model was evaluated by the corresponding P-value. $\mathrm{P}<0.05$ was considered statistically significant.

\section{Analytic sensitivity of the assay}

Analytic sensitivity, which is also known as the limit of detection, refers to the minimum amount of analyte that can be detected on a certain background levels (Clark et al. 2009). After the optimization formula is obtained, mixtures of standard Salmonella strains (at a concentration of $10^{1}$ cells $\mathrm{mL}^{-1}$ ) and E. coli (at a concentration of $10^{4}$ cells $\mathrm{mL}^{-1}, 10^{5}$ cells $\mathrm{mL}^{-1}$ or $10^{6}$ cells $\mathrm{mL}^{-1}$ ) were used to test the analytic sensitivity of our assay. They were diluted with sterile water to obtain serial dilutions, which were counted in duplicates on agar plates. Serial dilutions of bacteria were prepared using a turbidity meter (DensiCHEK Plus, BioMerieux). The prepared swabs were inserted into the above test tubes and cultured at $37^{\circ} \mathrm{C}$. The number of swabs that produced black spots were recorded in the corresponding time period (18-19 h, 23-24 h, 35-36 h, 47-48 h). Black spots were picked in situ as soon as possible. The subsequent identification procedures were in accordance with the International Commission of Microbiological Specializations on Food (ICMSF) (ICMSF 2011).

\section{Evaluation of the optimized medium on human feces samples}

Human fecal samples were collected using a disposable sampling stick, which was gently inserted into the volunteer's anus and repeatedly rotated to obtain suitable feces. Then the sampling stick was submerged in $2.00 \mathrm{~mL}$ of purified water and mixed well. A total of 4006 samples were collected and detected for Salmonella at the Wuhan Center for Disease Control and Prevention of China. Each sample was divided into two tubes $(1000 \mu \mathrm{L}$ per tube); one tube was detected by the conventional culture-based method according to standard ICMSF identification (ICMSF 2011), the other by the solid phase enrichment method. The swab was directly applied to sampling, culture, and isolation following the detection procedures as described earlier. The suspected black spots were isolated in situ onto XLD agar plates and identified using standard ICMSF identification (Andrews 1994; ICMSF 2011).

\section{Results}

\section{Optimization of the medium used in WSEA}

Based on the confirmation report from CCD operation and the above second-order polynomial model (Eq. 1), the Design-Expert of statistical software was employed to perform the stepwise regressions of experimental results from CCD (Table 2) to generate two quadratic polynomial models below:

$$
\begin{aligned}
\mathrm{Y} 1= & 97.35+10.77 \mathrm{X}_{1}+9.22 \mathrm{X}_{2}+6.31 \mathrm{X}_{3} \\
& -0.84 \mathrm{X}_{1} \mathrm{X}_{2}+1.01 \mathrm{X}_{1} \mathrm{X}_{3}-2.70 \mathrm{X}_{2} \mathrm{X}_{3} \\
& -11.67 \mathrm{X}_{1}^{2}-7.09 \mathrm{X}_{2}^{2}-5.78 \mathrm{X}_{3}^{2} \\
\mathrm{Y} 2= & 98.18+11.03 \mathrm{X}_{1}+8.89 \mathrm{X}_{2}+6.37 \mathrm{X}_{3} \\
& -2.50 \mathrm{X}_{1} \mathrm{X}_{2}+0.63 \mathrm{X}_{1} \mathrm{X}_{3}-3.75 \mathrm{X}_{2} \mathrm{X}_{3} \\
& -11.66 \mathrm{X}_{1}^{2}-8.57 \mathrm{X}_{2}^{2}-5.48 \mathrm{X}_{3}^{2}
\end{aligned}
$$

The variables were coded according to the above equations. The CCD system automatically generated 20 combinations from the three variables and the predicted 
Table 2 Predicted responses to central composite design with three independent variables

\begin{tabular}{|c|c|c|c|c|c|}
\hline Run & $\begin{array}{l}10 \% \text { ferric citrate } \\
\text { amine }(\mu \mathrm{L})\end{array}$ & $\begin{array}{l}20 \% \text { sodium } \\
\text { hyposulfite }(\mu \mathrm{L})\end{array}$ & $5 \%$ cystine $(\mu \mathrm{L})$ & Response 1 (\%) & Response 2 (\%) \\
\hline 1 & 9.00 & 12.00 & 7.00 & 96.30 & 97.50 \\
\hline 2 & 6.00 & 16.00 & 10.00 & 74.07 & 75.00 \\
\hline 3 & 14.05 & 12.00 & 7.00 & 85.19 & 85.00 \\
\hline 4 & 9.00 & 12.00 & 7.00 & 100.00 & 97.50 \\
\hline 5 & 6.00 & 8.00 & 4.00 & 52.50 & 47.50 \\
\hline 6 & 9.00 & 12.00 & 7.00 & 92.59 & 97.50 \\
\hline 7 & 6.00 & 8.00 & 10.00 & 66.67 & 65.00 \\
\hline 8 & 12.00 & 8.00 & 4.00 & 70.37 & 70.00 \\
\hline 9 & 3.95 & 12.00 & 7.00 & 37.04 & 40.00 \\
\hline 10 & 9.00 & 12.00 & 12.05 & 92.59 & 92.50 \\
\hline 11 & 12.00 & 16.00 & 4.00 & 85.19 & 85.00 \\
\hline 12 & 12.00 & 16.00 & 10.00 & 92.60 & 90.00 \\
\hline 13 & 6.00 & 16.00 & 4.00 & 74.07 & 72.50 \\
\hline 14 & 9.00 & 18.73 & 7.00 & 96.29 & 92.50 \\
\hline 15 & 12.00 & 8.00 & 8.00 & 85.19 & 90.00 \\
\hline 16 & 9.00 & 12.00 & 1.95 & 62.96 & 67.50 \\
\hline 17 & 9.00 & 12.00 & 7.00 & 96.30 & 100.00 \\
\hline 18 & 9.00 & 12.00 & 7.00 & 100.00 & 100.00 \\
\hline 19 & 9.00 & 12.00 & 7.00 & 100.00 & 97.50 \\
\hline 20 & 9.00 & 5.27 & 7.00 & 51.85 & 50.00 \\
\hline
\end{tabular}

Response 1 means the isolation rate of the 9 standard Salmonella; Response 2 means the isolation rate of 40 local Salmonella strains

responses are listed in Table 2 . The values were rounded for experimental convenience. Then the enrichment effects of 20 kinds of media on target bacteria were analyzed according to the production rate of hydrogen sulfide. ANOVA analysis showed that both Y1 (Additional file 2) and Y2 (Additional file 3) had a high adequate precision (Adeq $\mathrm{P})$ value $(\mathrm{Y} 1=10.77, \mathrm{Y} 2=15.40)$ (Table 3).

The actual model correlation coefficient was greater than 0.75 , which proved that the relevant model has better suitability (Brophy and Joseph 1997). In this study, the determination coefficients $\left(R^{2}\right)$ (0.9253 for $\mathrm{Y} 1$ and 0.9582 for $\mathrm{Y} 2$ ) indicated a good agreement between predicted and experimental values (Fig. 2). ANOVA and the corresponding post hoc contrast were used to evaluate the statistical significance and the goodness-of-fit of two models. The values of the adjusted determination coefficient-squared (Adj $\mathrm{R}^{2}$ ) $(0.8580$ for $\mathrm{Y} 1$ and 0.9206 for Y2) suggested that more than $85 \%$ of the variations were due to the three variables present in the models. Both the model $\mathrm{F}$ values for each of the response variables (Table 3) and the model P values (Table 4) implied that the models are significant with very low chance $(\leq 0.02 \%)$ that model $\mathrm{F}$ values $(11.13$ for $\mathrm{Y} 1,9.10$ for Y2) were large owing to noise. Furthermore, the models were all significant and reliable from the low Prob $>\mathrm{F}$ value $(\leq 0.001$ for $\mathrm{Y} 1$ and $\mathrm{Y} 2)$ and the relatively low variation coefficient (CV\%) value (8.69 for Y1, 6.56 for $\mathrm{Y} 2$ ) (Table 3). The significance of each term in the models was evaluated by their corresponding P-value. In general, the values less than 0.05 indicated that these terms were significant (Table 4). RSM analysis further revealed that the combination of $9.00 \mu \mathrm{L}$ of $10 \%$ ferric citrate amine, $12.00 \mu \mathrm{L}$ of $20 \%$ sodium hyposulfite, and $7.00 \mu \mathrm{L}$ of $5 \%$ cystine was an optimal combination for both amplification of Salmonella and inhibition of E. coli (Fig. 3). The related statistical analysis of the model terms by multiple regression was shown in Table 4. The results of visual observation were shown in Fig. 4.

Through this statistical experiment, we determined the optimal formula containing $0.60 \%$ polyvalent poly peptone, $0.40 \%$ buffered peptone water, $0.09 \%$ ferric citrate amine, $0.24 \%$ sodium hyposulfite, $0.035 \%$ cystine, $0.01 \mu \mathrm{g} \mathrm{mL}$ super absorbing polymer, $0.011 \%$ sodium deoxycholate, $15.00 \mu \mathrm{g} \mathrm{mL}{ }^{-1}$ ethyl green and $30.00 \mu \mathrm{g} \mathrm{mL} \mathrm{m}^{-1}$ sodium selenite. Ethyl green and sodium selenite were used as the bacterial inhibiting agents to improve the specificity of detection. The medium was named as $\mathrm{H}_{2} \mathrm{~S}$-producing medium and used for all the experiments. 
Table 3 ANOVA analysis of the predicted responses for quadratic polynomial models

\begin{tabular}{|c|c|c|c|c|c|c|c|}
\hline Group & Equation & Source & SS & DF & MS & F-value & Prob $>F$ \\
\hline \multirow[t]{5}{*}{ Y1 } & $\mathrm{CV} \%=8.69$ & Model (Y1) & 6080.75 & 9 & 675.64 & 13.76 & 0.0002 \\
\hline & $R^{2}=0.9253$ & Residual & 491.00 & 10 & 49.10 & & \\
\hline & $\operatorname{Adj}^{2}=0.8580$ & Lack-of-fit & 445.27 & 5 & 89.05 & 9.74 & 0.0130 \\
\hline & PredR ${ }^{2}=-0.4747$ & Pure error & 45.73 & 5 & 9.15 & & \\
\hline & Adeq $P=10.773$ & Total & 6571.75 & 19 & & & \\
\hline \multirow[t]{5}{*}{ Y2 } & $C V \%=6.56$ & Model (Y2) & 6418.45 & 9 & 713.16 & 25.47 & $<0.001$ \\
\hline & $R^{2}=0.9582$ & Residual & 279.98 & 10 & 28.00 & & \\
\hline & $\operatorname{Adj}^{2}=0.9206$ & Lack-of-fit & 271.65 & 5 & 54.33 & 32.60 & 0.0008 \\
\hline & PredR ${ }^{2}=0.6907$ & Pure error & 8.33 & 5 & 1.67 & & \\
\hline & AdeqP $=15.404$ & Total & 6698.44 & 19 & & & \\
\hline
\end{tabular}

SS sum of squares, $D F$ degrees of freedom, $M S$ mean squared, $C V \%$ variation coefficient, $R^{2}$ determination coefficient, $A d j R^{2}$ adjusted R-squared, $P r e d R^{2}$ predR-squared, A deqP adequate precision
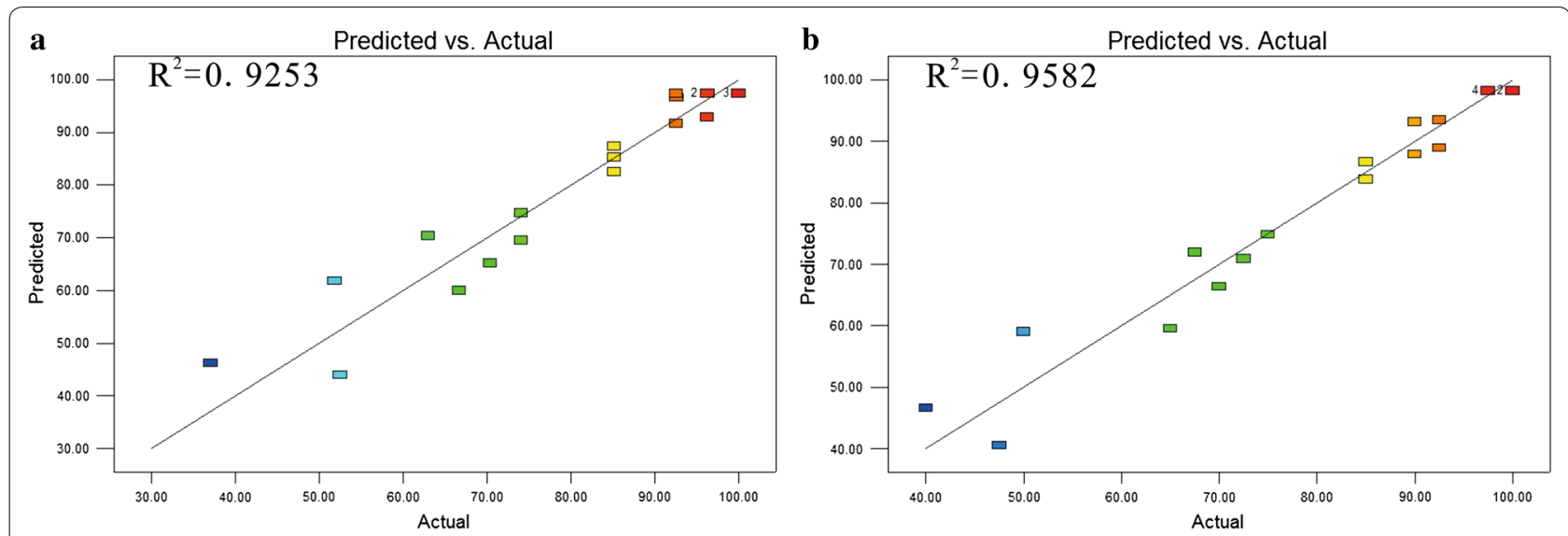

Fig. 2 The determination coefficients (R2) between predicted and experimental values: a R2 of mode $Y 1$, $\mathbf{b}$ R2 of mode $Y 2$

Table 4 Statistical analysis of model terms by multiple regression analysis

\begin{tabular}{|c|c|c|c|c|c|c|}
\hline \multirow[t]{2}{*}{ Term } & \multicolumn{3}{|l|}{ Y1 } & \multicolumn{3}{|l|}{ Y2 } \\
\hline & $\mathrm{CE}$ & SE & P-value & $\overline{\mathrm{CE}}$ & $\mathrm{SE}$ & P-value \\
\hline Intercept & 97.35 & 2.86 & 0.0002 & 98.18 & 2.16 & $<0.001$ \\
\hline$x_{1}$ & 10.77 & 1.90 & 0.0002 & 11.03 & 1.43 & $<0.0001$ \\
\hline$\times 2$ & 9.22 & 1.90 & 0.0007 & 8.89 & 1.43 & $<0.0001$ \\
\hline X3 & 6.31 & 1.90 & 0.0076 & 6.37 & 1.43 & $<0.0012$ \\
\hline$\times 1 \times 2$ & -0.84 & 2.48 & 0.7408 & -2.50 & 1.87 & 0.2110 \\
\hline$\times 1 \times 3$ & 1.01 & 2.48 & 0.6928 & 0.63 & 1.87 & 0.7452 \\
\hline$\times 2 \times 3$ & -2.70 & 2.48 & 0.3018 & -3.75 & 1.87 & 0.0728 \\
\hline$x_{1}^{2}$ & -11.67 & 1.85 & $<0.0001$ & -11.66 & 1.39 & $<0.0001$ \\
\hline$x_{2}^{2}$ & -7.09 & 1.85 & 0.0033 & -8.57 & 1.39 & 0.0001 \\
\hline$x_{3}^{2}$ & -5.78 & 1.85 & 0.0107 & -5.48 & 1.39 & 0.0028 \\
\hline
\end{tabular}

Y1 mode 1 (the nine type strains), Y2 mode 2 (the 40 different local strains), CE coefficient estimate, SE Squares for Error 


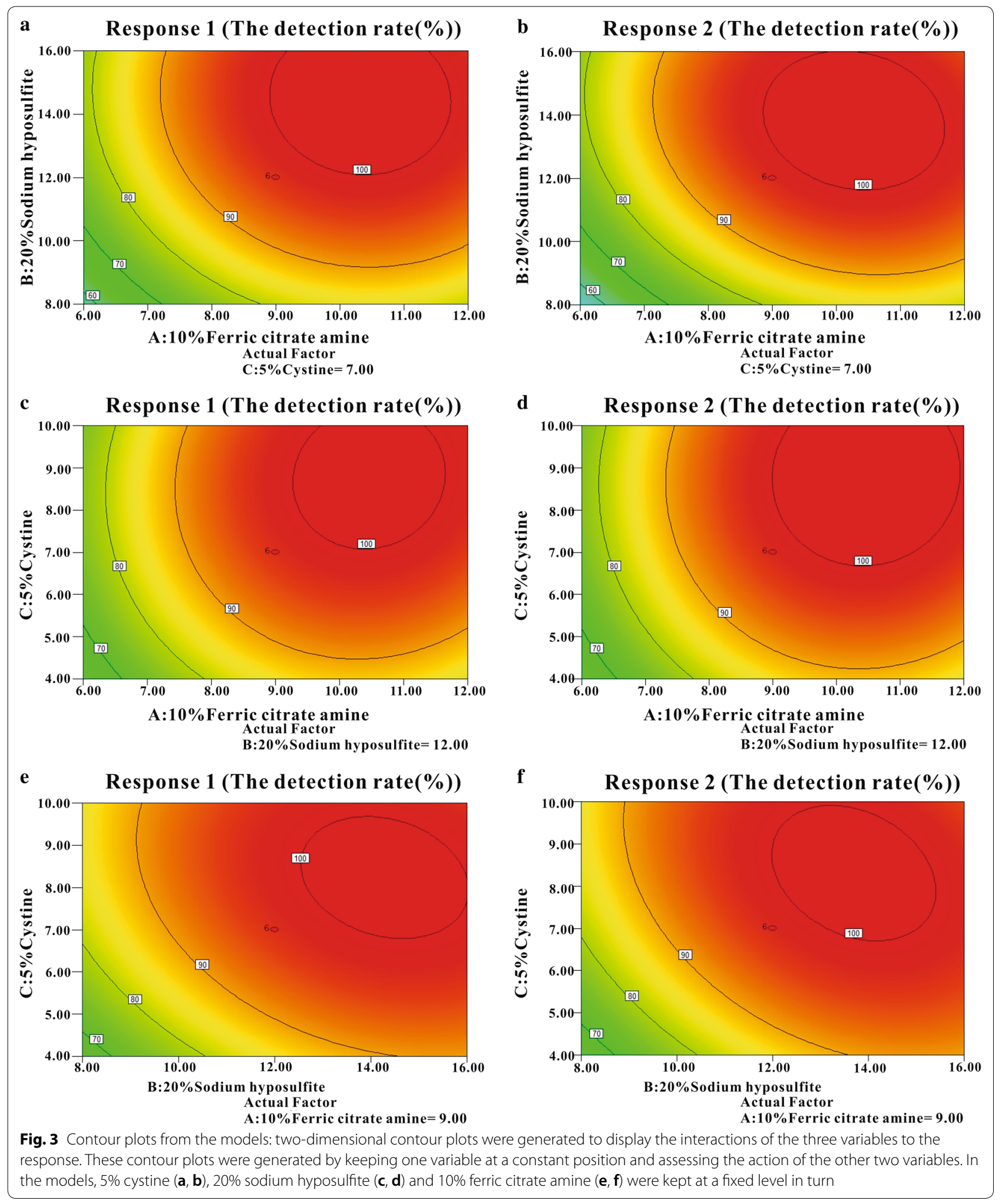




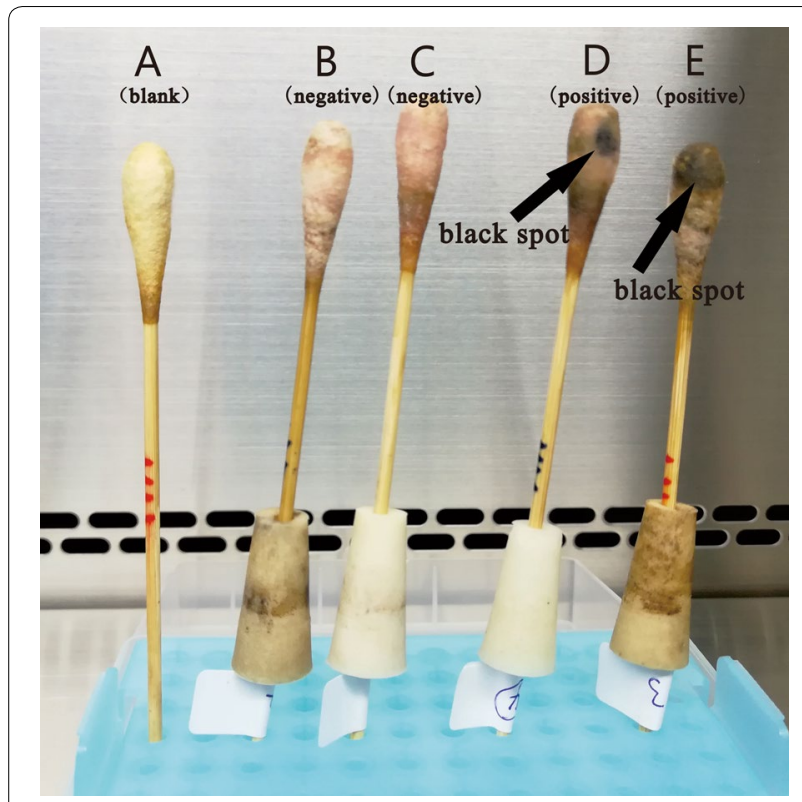

Fig. 4 Visual observation of the whole-sample solid-phase enrichment assay using the optimized $\mathrm{H}_{2} \mathrm{~S}$-producing medium: a prepared swab with no sample applied, b, c negative control (swabs with E. coli only), d, e swabs applied with $10^{1}$ cells of Salmonella and $10^{5}$ cells of E. coli

\section{Analytic sensitivity}

Our result showed that when the concentration of $E$. coli was $10^{4}$ cells $\mathrm{mL}^{-1}$ or $10^{5}$ cells $\mathrm{mL}^{-1}$, Salmonella was detected at a concentration of $10^{1}$ cells $\mathrm{mL}^{-1}$ at $37{ }^{\circ} \mathrm{C}$ for $24 \mathrm{~h}$. However, when the concentration of $E$. coli was $10^{6}$ cells $\mathrm{mL}^{-1}$, Salmonella $\left(10^{1}\right.$ cells $\left.\mathrm{mL}^{-1}\right)$ was not detectable at $37^{\circ} \mathrm{C}$ for $24 \mathrm{~h}, 36 \mathrm{~h}$ or $48 \mathrm{~h}$. Therefore, the analytic sensitivity was determined as $10^{1}$ cells $\mathrm{mL}^{-1}$ with a concentration of interfering bacteria $(E$. coli) at $10^{5}$ cells $\mathrm{mL}^{-1}$ at $37^{\circ} \mathrm{C}$ for $24 \mathrm{~h}$.

\section{Application of WSEA on human feces samples}

A total of 4006 samples were collected and synchronously detected for Salmonella by the conventional method and the optimized solid phase enrichment. The positive rate was $0.42 \%$ by the conventional culture-based method, and $2.12 \%$ by WSEA. The proportional positive rate was the highest in the 18th $\mathrm{h}(50.59 \%)$ according to the WSEA. The rate in the 21 th $h(38.82 \%)$ was the second and in the $24 \mathrm{~h}(9.41 \%)$ was the last (Table 5). To improve the detection efficiency, the distinguishment and isolation should be scheduled to be completed in 18-21 h.

\section{Discussion}

On the solid-phase support, the black spots formed by the ferrous sulfide on the swab provide targeted display that helps achieve in situ isolation of suspicious colonies. However, inappropriate media formula could lead to false positive or false negative in practical applications. It is crucial to design a universal and efficient WSEA to detect different serotypes of Salmonella.

In this study, we found that the amount of hydrogen sulfide produced by reduction of either cystine or sodium thiosulfate is different, depending the type of Salmonella. We have found that the proper proportion of cystine and sodium thiosulfate is important in the chromogenic medium of WSEA when detecting various serotypes of Salmonella.

As a powerful statistical tool for regression analysis, RSM is specifically applied to study the relationship among multiple factors (Karichappan et al. 2014). Variances had significant effect on regression analysis when adequate precision was greater than 4 (Ramanan et al. 2010). In the regression analysis, the high adequate precision (Adeq $\mathrm{P}$ ) value $(\mathrm{Y} 1=10.77, \mathrm{Y} 2=15.45)$ indicates that the model is suitable for predicting the responses. The fitness of the models was largely dependent on the determination coefficient (Montgomery 2001). Normally, the value of the determination coefficient $\left(R^{2}\right)$ ranges from 0 to 1 . The closer the value is to 1 , the better the model fits the data. Indeed, higher $\mathrm{R}^{2}(0.9253$ for $\mathrm{Y} 1$ and 0.9582 for Y2) indicated a good agreement between predicted and experimental values.

In RSM analysis, the two-dimensional contour plots (Fig. 3) were the graphical representations of the regression models and clearly spread the type and significance of interactions between the variances on the responses.

Table 5 Statistic comparison of traditional method and WSEA on human feces samples

\begin{tabular}{|c|c|c|c|c|c|c|c|c|c|}
\hline \multirow{3}{*}{$\begin{array}{l}\text { WCDC } \\
\text { group }\end{array}$} & \multirow{3}{*}{$\begin{array}{l}\# \\
\text { of samples }\end{array}$} & \multicolumn{2}{|c|}{ Traditional method } & \multicolumn{6}{|c|}{ Whole-sample solid-phase enrichment assay (WSEA) } \\
\hline & & \multirow{2}{*}{$\begin{array}{l}\text { Positive \# } \\
\text { (rate) }\end{array}$} & \multirow{2}{*}{$\begin{array}{l}\text { Positive \#/ } \\
\text { rate }\end{array}$} & \multicolumn{2}{|l|}{$18 \mathrm{~h}$} & \multicolumn{2}{|l|}{$21 \mathrm{~h}$} & \multicolumn{2}{|l|}{$24 \mathrm{~h}$} \\
\hline & & & & $\begin{array}{l}\text { Dark spots \# } \\
\text { (rate) }\end{array}$ & $\begin{array}{l}\text { Positive \# } \\
\text { (proportion) }\end{array}$ & $\begin{array}{l}\text { Dark spots \# } \\
\text { (rate) }\end{array}$ & $\begin{array}{l}\text { Positive \# } \\
\text { (proportion) }\end{array}$ & $\begin{array}{l}\text { Dark spots \# } \\
\text { (rate) }\end{array}$ & $\begin{array}{l}\text { Positive \# } \\
\text { (proportion) }\end{array}$ \\
\hline 1 & 1502 & $6(0.40 \%)$ & $31(2.06 \%)$ & $242(16.11 \%)$ & $16(51.61 \%)$ & $525(34.95 \%)$ & $12(38.71 \%)$ & $989(65.85 \%)$ & $3(9.68 \%)$ \\
\hline 2 & 1284 & $5(0.39 \%)$ & $36(2.8 \%)$ & $179(13.94 \%)$ & $19(52.78 \%)$ & $432(33.64 \%)$ & $14(38.89 \%)$ & $871(67.83 \%)$ & $3(8.33 \%)$ \\
\hline 3 & 1220 & $6(0.49 \%)$ & $18(1.48 \%)$ & $123(10.08 \%)$ & $9(50 \%)$ & 354 (29.02\%) & 7 (38.89\%) & 782 (64.10\%) & $2(11.11 \%)$ \\
\hline TOTAL & 4006 & $17(0.42 \%)$ & $85(2.12 \%)$ & $544(13.58 \%)$ & $43(50.59 \%)$ & 1311 (32.73\%) & 33 (38.82\%) & 2642 (65.95\%) & $8(9.41 \%)$ \\
\hline
\end{tabular}


The elliptical or saddle contour plot showed the interaction significant (Montgomery 2001). The interaction between B (sodium hyposulfite) and C (cystine) had the highest effect on Salmonella; the interaction between A (ferric citrate amine) and B (sodium hyposulfite) was the second, and the interaction between A (ferric citrate amine) and $C$ (cystine) was the last. The exploration on interactions between the factors by the contour plots was helpful in selecting variable ranges to achieve the best optimization.

We successfully employed RSM to develop a solid phase enrichment medium, which included multiple components that could affect the effectiveness of the medium. The optimized WSEA was tested with 4006 patients' fecal samples and was proven to be effective, further confirming that RSM may have broader applications on experimental designs in the biomedical and clinical fields. Compared with the traditional culture-based method, the positive detection rate from the solid phase enrichment method was more than five times higher. A critical requirement for WSEA is careful observation between the 18th to 21 th $\mathrm{h}$ of the culture. When the ferrous sulfide-produced black spots spread, the accuracy of isolation for targeted bacteria will decrease due to the blurred positioning of the colony.

The conventional culture-based method for Salmonella detection has three main deficiencies. First, the biggest challenge of the traditional enrichment method is the difficulty in providing adequate buffering and protection for targeted bacteria, which directly affects effective recovery and expansion. Under the cyclical antagonism of all nontargeted bacteria, damaged bacteria cannot compete with non-targeted bacteria on the order of magnitude. Second, the traditional method only transfers a loop amount (about $5 \mu \mathrm{L}$ ) from the "pre-enrichment liquid" into the enrichment liquid or the agar plate, which cannot achieve the utilization of a full sample. Third, the low efficiency of traditional detection methods seriously restricts the effective monitoring of public health; it takes 3 to 5 days to obtain any positive or negative results (ICMSF 2011; Velusamy et al. 2010). Due to these constraints, much effort has been devoted to the development of rapid detection technologies, including the enzyme-linked immunosorbent assay (Mirhosseini et al. 2017), polymerase chain reaction (Zhang et al. 2018), and DNA hybridization (Carloni et al. 2018). However, these methods normally require specific immunological or genetic markers, and the diagnosis is often uncertain due to the lack of living bacteria (Tang et al. 2016).

The solid phase enrichment method overcomes many of the drawbacks indicated above. It is capable of adsorbing medium and sample. The selective and chromogenic medium used on this swab can achieve sensitive amplification of target bacteria and form chromogenic colonies in situ based on a biochemical reaction. Using naturally degreased cellulose with good biocompatibility (Langer and Tirrell 2004), the fibrous network on the cellulose-based swab provides the site for cell attaching, amplification, and colony formation in situ. Moreover, the culture space in swab is divided into several regions with the semi-mobile phase, which greatly reduces the antagonism of non-targeted bacteria in the sample. It also provides sufficient buffer and protection for the trace or damaged target bacteria. In our current study, we showed that cellulose-based swabs are not only effective in absorbing medium for the chromogenic reaction but are also conducive to the antagonism against non-targeted bacteria, possibly due to their large sizes.

Compared to the previously developed immunosensor technique, the WSEA developed in this study also has some advantages (Tang et al. 2016). First, the enrichment medium was optimized using the response surface methodology, an excellent statistical tool for regression analysis. The optimized medium is broadly applicable to a variety of Salmonella serotypes. Second, the supplementary inhibiting ingredients were determined as ethyl green $15 \mu \mathrm{g} \mathrm{mL} \mathrm{g}^{-1}$ and sodium selenite $30 \mu \mathrm{g} \mathrm{mL}^{-1}$. The inhibiting ingredients significantly improved the specificity of Salmonella detection. Third, the absorption capacity of the swab was enlarged from 600 to $1000 \mu \mathrm{L}$, so that bacteria in the sample were dispersed more widely, which is more conducive to the antagonism of trace Salmonella against local non-targeted bacteria. In addition, it is difficult to use the immunosensor technique for large-scale detection. It requires expensive instrument, such as laser scanning confocal microscope, and difficult to prepare the specialized bio-probe reagent at large scale. Through this study, the optimized formulation on solid phase enrichment by RSM allows relatively quick, low-cost, and large-scale detection of Salmonella, which could be used in many developing countries. With the role of RSM, We anticipate that commercial products based on this solid phase enrichment detection method for foodborne pathogens will be available soon.

\section{Additional files}

Additional file 1. Raw operational data in the central composite design (CCD) in response surface methodology (RSM).

Additional file 2. The predicted response for the nine standard Salmonella strains (Y1)

Additional file 3. The predicted response for the forty Salmonella strains from local patients (Y2). 


\section{Abbreviations}

WSEA: whole-sample solid-phase enrichment assay; $\mathrm{H}_{2} \mathrm{~S}$ : hydrogen sulfide: RSM: response surface methodology; XLD: Xylose Lysine Deoxycholate; MSRV: modified semi-solid rappaport vassiliadis; CCD: central composite design; ANOVA: analysis of variance; ICMSF: International Commission of Microbiological Specializations on Food.

\section{Acknowledgements}

The authors thank to Wuhan Center for Disease Control and Prevention in China for the experimental materials provided to us.

\section{Authors' contributions}

FT designed the experiments, provided experimental fund and wrote the manuscript. FT, ZC, HZ, JL, WJL, YZ and ML executed the experiments, collected and analyzed all data. FT and FW contributed to experimental theory. HYH, WYL, HX, ZJC, JH and HMP provided technical support. YX was responsible for initiation and supervision of the study. YX, HMP, WJL and ZJC participated in the provided critical review of the manuscript. All authors read and approved the final manuscript.

\section{Funding}

This work was funded by the General Program of Health and Family Planning Commission of Hubei Province of China (Grant No. WJ2017M194), the General Program of Natural Science Foundation of Hubei Province of China (Grant No. 2017CFB709), the Frontier Project of Application Foundation of Wuhan Science and Technology Bureau of China (Grant No. 2018060401011314) and the National Mega Project on Major Infectious Disease Prevention of China (Grant No. 2017ZX10103005-007-001)

\section{Availability of data and materials}

The data supporting the conclusions are presented in the main article and additional material.

\section{Ethics approval and consent to participate}

The protocol of this study was approved by the Human Research Advisory Committees of the Wuhan Center for Disease Control and Prevention and the Wuhan Children's Hospital for Medical Sciences. All procedures performed in studies involving human participants were in accordance with the ethical standards of the institutional and/or national research committee and with the 1964 Helsinki declaration and its later amendments or comparable ethical standards. The anal specimens involved in the study were from the medical examiners on catering service practitioners. All participation was voluntary and agreed to participate in the methodological comparative study. The medical reports were still based on the results of the national standard test method.

\section{Consent for publication}

\section{Not applicable.}

\section{Competing interests}

The authors declare that they have no competing interests.

\section{Author details}

1 Department of Laboratory Medicine, Wuhan Children's Hospital (Wuhan Maternal and Child Healthcare Hospital), Tongji Medical College, Huazhong University of Science \& Technology, Wuhan 430016, People's Republic of China. ${ }^{2}$ Microbiological Laboratory, Wuhan Center for Disease Control and Prevention, Wuhan 430015, People's Republic of China. ${ }^{3}$ Department of Laboratory Medicine, Tongji Hospital, Tongji Medical College, Huazhong University of Science and Technology, Wuhan 430030, People's Republic of China. ${ }^{4}$ Biobank, Wuhan Children's Hospital (Wuhan Maternal and Child Healthcare Hospital), Tongji Medical College, Huazhong University of Science \& Technology, Wuhan 430016, People's Republic of China. ${ }^{5}$ Institute of Environmental Safety, Wuhan Academy of Agricultural Sciences, Wuhan 430072, People's Republic of China. ${ }^{6}$ Microbiological Laboratory, Qiaokou District Center for Disease Control and Prevention, Wuhan 430030, People's Republic of China. ${ }^{7}$ Gastroenterology Department, Wuhan Children's Hospital (Wuhan Maternal and Child Healthcare Hospital), Tongji Medical College, Huazhong University of Science \& Technology, Wuhan 430016, People's Republic of China. ${ }^{8}$ Microbiological Laboratory, Jianghan District Center for Disease Control and Prevention, Wuhan 430030, People's Republic of China. ${ }^{9}$ Hospital Acquired Infection Control Department, Wuhan Children's Hospital (Wuhan Maternal and Child
Healthcare Hospital), Tongji Medical College, Huazhong University of Science \& Technology, Wuhan 430016, People's Republic of China. ${ }^{10}$ Key Laboratory of Analytical Chemistry for Biology and Medicine (Ministry of Education), College of Chemistry and Molecular Sciences, State Key Laboratory of Virology, Wuhan University, Wuhan 430072, People's Republic of China.

Received: 15 March 2019 Accepted: 18 June 2019

Published online: 28 June 2019

\section{References}

Abd Elrazak A, Ward AC, Glassey J (2013) Response surface methodology for optimising the culture conditions for eicosapentaenoic acid production by marine bacteria. J Ind Microbiol Biotechnol 40:477-487

Andrews WH (1994) Update on validation of microbiological methods by AOAC International. J AOAC Int 77:925-931

Bell RL, Jarvis KG, Ottesen AR, McFarland MA, Brown EW (2016) Recent and emerging innovations in Salmonella detection: a food and environmental perspective. Microb Biotechnol 9:279-292

Brophy JM, Joseph L (1997) Bayesian interim statistical analysis of randomised trials. Lancet 349:1166-1168

Carloni E, Rotundo L, Brandi G, Amagliani G (2018) Rapid and simultaneous detection of Salmonella spp., Escherichia coli O157, and Listeria monocytogenes by magnetic capture hybridization and multiplex real-time PCR. Folia Microbiol (Praha) 63:735-742

Clark RB, Lewinski MA, Loeffelholz MJ, Tibbetts RJ (2009) Cumitech 31A: verification and validation of procedures in the clinical microbiology laboratory. In: Sharp SE (ed) Coordinating. ASM Press, Washington, DC

Dastkhoon M, Ghaedi M, Asfaram A, Arabi M, Ostovan A, Goudarzi A (2017) Cu@SnS/SnO2 nanoparticles as novel sorbent for dispersive micro solid phase extraction of atorvastatin in human plasma and urine samples by high-performance liquid chromatography with UV detection: application of central composite design (CCD). Ultrason Sonochem 36:42-49

Gong C, Liu X, Jiang X (2014) Application of bacteriophages specific to hydrogen sulfide-producing bacteria in raw poultry by-products. Poult Sci 93:702-710

ICMSF (2011) Microorganisms in foods 8-microbial testing in food safety management, 1ed. Kluwer Academic/Plenum Publishers, New York

Jackson BR, Griffin PM, Cole D, Walsh KA, Chai SJ (2013) Outbreak-associated Salmonella enterica serotypes and food Commodities, United States, 1998-2008. Emerg Infect Dis 19:1239-1244

Jin C, Gibani MM, Moore M, Juel HB, Jones E, Meiring J, Harris V, Gardner J, Nebykova A, Kerridge SA, Hill J, Thomaides-Brears H, Blohmke CJ, Yu LM, Angus B, Pollard AJ (2017) Efficacy and immunogenicity of a Vi-tetanus toxoid conjugate vaccine in the prevention of typhoid fever using a controlled human infection model of Salmonella Typhi: a randomised controlled, phase 2b trial. Lancet 390:2472-2480

Karichappan T, Venkatachalam S, Jeganathan PM (2014) Optimization of electrocoagulation process to treat grey wastewater in batch mode using response surface methodology. J Environ Health Sci Eng 12:29

Langer R, Tirrell DA (2004) Designing materials for biology and medicine. Nature 428:487-492

Langley G, Besser J, Iwamoto M, Lessa FC, Cronquist A, Skoff TH, Chaves S, Boxrud D, Pinner RW, Harrison LH (2015) Effect of culture-independent diagnostic tests on future emerging infections program surveillance. Emerg Infect Dis 21:1582-1588

LaRock DL, Chaudhary A, Miller SI (2015) Salmonellae interactions with host processes. Nat Rev Microbiol 13:191-205

Li B, Gan L, Owens G, Chen Z (2018) New nano-biomaterials for the removal of malachite green from aqueous solution via a response surface methodology. Water Res 146:55-66

Majowicz SE, Musto J, Scallan E, Angulo FJ, Kirk M, O'Brien SJ, Jones TF, Fazil A, Hoekstra RM (2010) The global burden of nontyphoidal Salmonella gastroenteritis. Clin Infect Dis 50:882-889

Marder EP, Cieslak PR, Cronquist AB, Dunn J, Lathrop S, Rabatsky-Ehr T, Ryan P, Smith K, Tobin-D’Angelo M, Vugia DJ, Zansky S, Holt KG, Wolpert BJ, Lynch M, Tauxe R, Geissler AL (2017) Incidence and trends of infections with pathogens transmitted commonly through food and the effect of increasing use of culture-independent diagnostic tests on 
surveillance_foodborne diseases active surveillance network, 10 U.S. Sites, 2013-2016. MMWR Morb Mortal Wkly Rep 66:397-403

Mirhosseini SA, Fooladi AAl, Amani J, Sedighian H (2017) Production of recombinant flagellin to develop ELISA-based detection of Salmonella Enteritidis. Braz J Microbiol 48:774-781

Montgomery DC (2001) Response surface methods and other approaches to process optimization. In: Montgomery DC (ed) Design and analysis of experiments. John Wiley and Sons, New York, pp 427-510

Mousavi SJ, Parvini M, Ghorbani M (2018) Experimental design data for the zinc ions adsorption based on mesoporous modified chitosan using central composite design method. Carbohydr Polym 188:197-212

Ramanan RN, Tan JS, Mohamed MS, Ling TC, Tey BT, Ariff AB (2010) Optimization of osmotic shock process variables for enhancement of the release of periplasmic interferon- $a 2 b$ from Escherichia coli using response surface method. Process Biochem 45:196-202

Scallan E, Hoekstra RM, Angulo FJ, Tauxe RV, Widdowson MA, Roy SL, Jones JL, Griffin PM (2011) Foodborne illness acquired in the United States-major pathogens. Emerg Infect Dis 17:7-15

Tam YJ, Allaudin ZN, Lila MA, Bahaman AR, Tan JS, Rezaei MA (2012) Enhanced cell disruption strategy in the release of recombinant hepatitis $B$ surface antigen from Pichia pastoris using response surface methodology. BMC Biotechnol 12:70

Tang F, Pang DW, Chen Z, Shao JB, Xiong LH, Xiang YP, Xiong Y, Wu K, Ai HW, Zhang H, Zheng XL, Lv JR, Liu WY, Hu HB, Mei H, Zhang Z, Sun H, Xiang Y,
Sun ZY (2016) Visual and efficient immunosensor technique for advancing biomedical applications of quantum dots on Salmonella detection and isolation. Nanoscale 8:4688-4698

Velusamy V, Arshak K, Korostynska O, Oliwa K, Adley C (2010) An overview of foodborne pathogen detection: in the perspective of biosensors. Biotechnol Adv 28:232-254

Verma T, Wei X, Lau SK, Bianchini A, Eskridge KM, Stratton J, Anderson NM, Thippareddi H, Subbiah J (2018) Response surface methodology for Salmonella inactivation during extrusion processing of oat flour. J Food Prot 81:815-826

Zhang QY, Zhou WW, Zhou Y, Wang XF, Xu JF (2012) Response surface methodology to design a selective co-enrichment broth of Escherichia coli, Salmonella spp. and Staphylococcus aureus for simultaneous detection by multiplex PCR. Microbiol Res 167:405-412

Zhang P, Zhuang L, Zhang D, Xu J, Dou X, Wang C, Gong J (2018) Serovarspecific polymerase chain reaction for detection of Salmonella enterica serovar Indiana. Foodborne Pathog Dis 15:776-781 (Epub ahead of print)

\section{Publisher's Note}

Springer Nature remains neutral with regard to jurisdictional claims in published maps and institutional affiliations.

\section{Submit your manuscript to a SpringerOpen ${ }^{\circ}$ journal and benefit from:}

- Convenient online submission

- Rigorous peer review

- Open access: articles freely available online

- High visibility within the field

- Retaining the copyright to your article

Submit your next manuscript at $\boldsymbol{\nabla}$ springeropen.com 